\title{
Estágio de docência na formação do mestre em enfermagem: relato de experiência
}

Recebido em: 31/05/2012
Aceito em: 12/07/2012
Maria Luiza Carvalho de Oliveira' Nair Chase da Silva ${ }^{2}$

Estágio de docência é parte integrante da formação do pós-graduando, objetivando a preparação para a docência e a qualificação do ensino de graduação. Objetivou-se, neste artigo, descrever a experiência vivenciada no estágio de docência junto à disciplina Educação em Saúde. O artigo apresenta um relato de experiência da mestranda do Curso de Mestrado em Enfermagem. Esta experiência torna-se importante a partir do momento em que oferece ao mestrando uma visão da prática em docência, uma vez que um dos objetivos do curso de pós-graduação acadêmico tem o intuito de formar profissionais qualificados para atuar na docência.

Descritores: Estágio de Docência, Enfermagem, Ensino.

\section{Teaching training in teacher nursing in the post-graduation program: experience report}

The teaching training is an integral part of the post-graduation, aiming at the preparation for teaching, and the qualification in the graduation teaching. The aim of this paper is describing an experience on the teaching training within the subject Education on Health. The article is an experience report of a Master Course in Nursing scholar. This experience becomes important from the moment that offers a vision of the teaching practice to the Master's scholar, since the post-graduate academic course aims to form professionals qualified to work in teaching, helping the educational process development.

Descriptors: Teaching Training, Nursing, Teaching.

\section{Formación laboral en enseñanza en la formación del profesorado en enfermería: relato de experiencia}

Formación laboral en enseñanza es una parte integral de la formación del alumno de postgrado, con miras a la preparación para la enseñanza, y la calificación de la enseñanza en la graduación. El objetivo de este artículo es describir una experiencia en la formación laboral en enseñanza en el escenario de la disciplina Educación en Salud. El artículo es un relato de experiencia de una alumna del Curso de Maestría en Enfermería. Esta experiencia es importante desde el momento en que ofrece al alumno de Maestría una visión de la práctica de la enseñanza, ya que el curso de postgrado académico pretende formar a profesionales capacitados para actuar en la enseñanza, ayudando a desarrollar el proceso educativo.

Descriptores: Formación Laboral, Enfermería, Enseñanza.

\section{INTRODUÇÃO}

A pós-graduação stricto sensu em Enfermagem no Brasil vem crescendo nos últimos 30 anos e tem contribuído para melhorar a qualificação dos enfermeiros. Observa-se, na atualidade, que os mestres e doutores são mais capacitados para o desenvolvimento de pesquisas, mas também estão sendo preparados para exigências próprias da educação em nível superior ${ }^{(1)}$.

O Estágio de Docência foi instituído pela Coordenação de Aperfeiçoamento de Pessoal de Nível Superior (CAPES) em 1999, desencadeando nas instituições que oferecem programas de mestrado e doutorado normas para sua operacionalização. Esta prática é uma atividade curricular para estudantes de cursos de pós-graduação stricto sensu. Os cursos de pós-graduação stricto sensu foram organizados com o objetivo de formar professores competentes para atender a expansão do ensino superior, elevar os níveis de qualidade do ensino oferecido e contribuir para o desenvolvimento de pesquisa científica(2).

Os propósitos dos cursos de mestrado e doutorado apontados pela Coordenação de Aperfeiçoamento de Pessoal de Nível Superior (CAPES) estão voltados para o desenvolvimento científico-tecnológico, assim como ao preparo para a docência ${ }^{(2)}$. Tendo em vista a possibilidade de atuação na atividade docente, a CAPES, em $1999^{(3)}$, tornou obrigatória a participação em estágio supervisionado parte das atividades de bolsistas, alunos de mestrado e doutorado sob sua tutela, apontando para a necessidade de alguma formação de caráter pedagógico para aqueles que, realizando cursos de pós-graduação, têm na atividade docente em nível superior um campo de trabalho possível. Essa atividade está descrita na Resolução 065/99, alterada pela Resolução 013/00 da CAPES(4).

A normatização da atividade de estágio de docência está contida na Portaria n. ${ }^{\circ} 76$, de 14 de abril de $2010^{(5)}$, que revoga a Portaria n. ${ }^{\circ}$ 52, de 26 setembro de 2002 da CAPES, quando estabelece que o mestrando/doutorando seja inserido em atividades de ensino sob a supervisão do professor orientador ${ }^{(6)}$. O estágio de docência é parte integrante da formação do

1Enfermeira. Mestranda do Programa de Pós-Graduação em Enfermagem da Universidade Federal do Amazonas - UFAM - em associação ampla com a Universidade Estadual Pará - UEPA. Manaus-AM. Contato: xmarialuizacarvalho@gmail.com

2 Enfermeira. Professora Doutora da Escola de Enfermagem de Manaus - EEM da Universidade Federal do Amazonas - UFAM. 
pós-graduando, objetivando a preparação para a docência, sendo a qualificação do ensino de graduação obrigatória para todos os bolsistas do Programa de Demanda Social ${ }^{(5)}$. De acordo com essa portaria, fica estabelecido que a duração mínima do estágio de docência será um semestre para o mestrado, com duração máxima de dois semestres. As atividades do estágio de docência deverão ser compatíveis com a área de pesquisa do programa de pós-graduação realizado pelo pós-graduando.

Sob normas dessa portaria, a mestranda teve a oportunidade de realizar o Estágio de Docência como aluna regular do Curso de Mestrado em Enfermagem da Universidade Federal do Amazonas/UFAM. O estágio aconteceu no primeiro semestre de 2012, na disciplina Educação em Saúde contida no Projeto Pedagógico de Curso, ministrada aos alunos do $3^{\circ}$ período do Curso de Graduação da UFAM.

A concepção de prática docente no estágio de docência procurou ampliar a dimensão científica da pós-graduação e dos saberes inerentes à profissão de enfermagem na tentativa de se afastar do "quem sabe fazer, sabe ensinar", para ancorar no conhecimento pedagógico propriamente dito ${ }^{(7)}$.

\section{OBJETIVO}

Descrever a experiência vivenciada no estágio de docência junto à disciplina Educação em Saúde.

\section{METODOLOGIA}

Relato de experiência de mestranda do Curso de Mestrado do Programa de Pós-

"A concepção de prática docente no estágio de docência procurou ampliar a dimensão científica da pós-graduação e dos saberes inerentes à profissão" planejar e realizar atividades educativas em saúde para grupos específicos, sob supervisão docente. Este ano, optou-se por trabalhar com adolescentes com o objetivo de oportunizar aos acadêmicos uma experiência diferente das até então adotadas, quando sempre foram privilegiados os grupos por agravos prevalentes, em detrimento dos grupos por ciclo de vida. A iniciativa também foi motivada pela intenção de ampliar a parceria construída com a Secretaria Municipal de Saúde de Manaus-AM e com a Secretaria Municipal de Educação. Desse modo, privilegiou-se o Programa Saúde na Escola (PSE). A disciplina Educação em Saúde tem como objetivo geral "instrumentalizar os alunos para o desenvolvimento de práticas educativas em saúde individuais e coletivas que promovam a autonomia e contribuam ao processo de construção da cidadania", abordando os seguintes temas: concepções sobre a educação, comunicação e participação; o Sistema Único de Saúde; o Programa Saúde na Escola; construção do plano educativo; a prática educativa em saúde na formação dos profissionais de saúde/ enfermagem $^{(8)}$.

$\mathrm{Na}$ fase de planejamento, foi apresentado à mestranda o Plano de Ensino da disciplina e suas inter-relações com as Diretrizes Curriculares Nacionais para o Curso de Enfermagem e o Projeto Pedagógico de Curso. Como a primeira versão do plano de ensino foi construída antes da inserção da mestranda, sendo posteriormente aprovada no Departamento de vinculação da disciplina, a aproximação da mesma consistiu em acompanhar as mudanças produzidas a partir da aplicação do pré-teste aos acadêmicos e definição dos cenários de prática. Nessa fase foram definidos os conteúdos teóricos a serem ministrados pela mestranda, que foi orientada sobre a elaboração do plano de aula. Tal atividade permitiu o resgate dos temas trabalhados na disciplina Metodologia de Ensino e Educação em Enfermagem, disciplina eletiva do Curso de Mestrado cursada no semestre anterior.

$\mathrm{Na}$ fase de execução do plano de ensino, a mestranda colocou em movimento o planejamento da disciplina, participando da aplicação do pré-teste e seus desdobramentos, inclusão de temas para melhor atender à necessidade de aprendizagem dos alunos, com ajustes previstos, haja vista o caráter flexível de todo o planejamento. Participou das atividades em sala de aula que envolveram ministração de aulas teóricas, acompanhamento de dinâmicas de grupo, supervisão e avaliação dos acadêmicos nas aulas práticas. Para a realização das aulas práticas, a mestranda estabeleceu contato prévio com a escola municipal de educação e com a unidade básica de saúde, ambas situadas na zona oeste do município, espaço no qual as atividades educativas foram realizadas. Os temas trabalhados com os adolescentes foram sugeridos em reuniões, tendo como base a programação do PSE, agendados semanalmente.

$\mathrm{Na}$ fase de avaliação, a mestranda acompanhou sua 
realização em todas as etapas, tanto no bloco teórico, quanto no prático, iniciando com a avaliação diagnóstica. Promoveu individualmente a avaliação de desempenho dos acadêmicos, após cada atividade educativa realizada. Participou de reuniões de avaliação, tanto do desenvolvimento da disciplina, quanto do desempenho de seu estágio em docência. Tais reuniões foram balizadas pela ação-reflexão-ação como estratégia para dar sentido à iniciação na prática docente. Nessas ocasiões foram discutidas facilidades e dificuldades enfrentadas, aplicação dos conhecimentos adquiridos ao longo da vida, e contribuição dos teóricos da educação na formação do enfermeiro docente.

\section{RESULTADOS E DISCUSSÃO}

OEstágiodeDocência proporcionouàmestrandaaoportunidade de acompanhar o planejamento, desenvolvimento e avaliação da disciplina, ao dar-lhe a chance de participar de reuniões sobre assuntos relativos às especificidades da clientela, dos conteúdos programáticos, dos recursos de ensino, dos objetivos a serem alcançados. Tais discussões foram travadas com professores da disciplina, monitora e acadêmicos matriculados, o que permitiu melhor aproveitamento dos recursos oferecidos e otimizar as aulas teóricas e práticas.

A participação da mestranda deu-se também no preparo de aulas, ministradas sob supervisão da coordenadora da disciplina. A discussão de estratégias de ensino e elaboração de plano de supervisão das atividades práticas foram, também, atividades realizadas. Desse modo foi possível contribuir para a formação dos alunos em diferentes atividades, aproximando teoria e prática, ao mesmo tempo em que promoveu sua própria formação. Desenvolveu e observou o trabalho docente na condução dos alunos no campo da educação para o cuidado, refletindo com os alunos sobre o componente educativo da prática do enfermeiro.

O Estágio de Docência promoveu um encontro da vivência como enfermeira assistencial com a prática pedagógica da docência, o que fez a mestranda meditar sobre sua prática. Analisou como a experiência na assistência de enfermagem torna-se um importante aliado em sala de aula, estimulando o confronto da prática com a teoria. Alunos de graduação exigem associação da teoria com a prática para melhor assimilação do conteúdo, e por isso a experiência assistencial do docente é um complemento para o aprendizado.

Aspecto valorizado no decorrer das práticas educacionais desenvolvidas, o exercício da docência requer algumas habilidades do professor, que estimulem o discente e favoreçam a concretização do processo ensino-aprendizagem. Quanto a essa questão, pode-se afirmar que o Estágio de Docência estimulou a mestranda a construir tais habilidades, seja pela postura do professor como mediador da aprendizagem, seja pela postura de facilitador da aprendizagem que possibilite ao aluno uma comunicação acessível. Nesse sentido compartilha a ideia de que o docente deve favorecer situações que estimulem a iniciativa e o diálogo entre o discente e o docente, bem como o diálogo com o saber acumulado historicamente e situações que despertem o interesse dos discentes na apropriação do conhecimento $^{(9)}$.

Junto aos professores da disciplina, a mestranda buscou estratégias que fortalecessem a participação dos discentes em atividades como, por exemplo, a realização de dinâmicas de grupo, trabalhos em equipe, leitura e discussão de textos selecionados e debate em sala de aula. Essas habilidades dizem respeito a saber ouvir e saber se comunicar de forma clara e objetiva, manter-se perante os discentes como um mediador do conhecimento e não como um detentor do saber. Contribuem também para subsidiar o desenvolvimento de práticas saudáveis em sala de aula, que produzam a construção do conhecimento mediante a segurança em relação ao conteúdo a ser abordado e a humildade no reconhecimento das nossas limitações, enquanto seres em processo de aprendizagem constante ${ }^{(10)}$. Destacam--se estas como algumas das habilidades desenvolvidas ao longo das vivências enquanto participante do processo educativo.

Outro aspecto de grande valia foi a experiência de utilizar estratégias pedagógicas onde o educador se torna educandoe oeducando se torna educador para que haja o processo educacional ${ }^{(11)}$. Estagiar/atuar nessa perspectiva chamou a atenção da mestranda, pois essa oportunidade a fez refletir sobre a contribuição no processo educativo discente e de como a participação do outro, enquanto sujeito de sua própria educação, é fundamental para a concretização do processo ensino-aprendizagem.

Esse momento de iniciação foi muito importante, desde o planejar a aula, passando pela execução, até a avaliação. Para o planejamento foi necessário pesquisar diferentes tipos de materiais didáticos, estudar e confeccioná-los, e elaborar estratégias para melhor abordar os conteúdos de ensino. Isso passou a ser importante como trabalho coletivo, por proporcionar a troca de ideias e informações, que contribuíram de maneira significativa para a atuação em sala de aula e não somente para a primeira aula, mas por todo no período de estágio.

A situação vivenciada corrobora estudos que mostram a importância da experiência do Estágio de Docência para pós-graduandos, apontada como básica e de relevância para a formação do docente universitário(12). Ademais, o vivenciado no Estágio de Docência mostrou com clareza a possibilidade de aliar pesquisa e ensino, instigando pelas situações que emergiram, tornando-se uma estratégia bastante interessante no processo de formação de novos docentes.

\section{CONCLUSÃO}


Para atender às novas perspectivas da prática docente na educação em enfermagem, é necessário habilitar os pós-graduandos para a formação de alunos críticos, reflexivos e criativos, capazes de comprometerem-se com a construção de uma prática profissional enriquecedora. Para isso ocorrer, é exigido do pós-graduando, além do domínio da prática assistencial, a construção de uma preparação na docência. O Estágio de Docência permite uma primeira aproximação com a prática profissional e promove a aquisição de um saber, de um saber fazer e as consequências das ações didáticas e pedagógicas desenvolvidas no quotidiano profissional do docente.

Ademais, integração entre pósgraduandos e graduandos é uma estratégia positiva no processo ensino/ aprendizagem, pois favorece a troca de experiências e permite que o pósgraduando seja inserido no atual contexto da formação profissional na sua área. Nessa perspectiva, a experiência de participar do Estágio de Docência do Programa de Pós-Graduação Mestrado em Enfermagem revelou-se de fundamental importância como parte integrante da formação da mestranda. Ao retornarem às salas de aula e ao convívio com os alunos da graduação, os pós-graduandos têm a oportunidade de se confrontar com uma nova perspectiva, face às mudanças nos processos educacionais que ocorrem em diversos sentidos. Atividades para a docência voltadas para os pós-graduandos estão repletas de oportunidades ímpares de vivenciar a prática do ensino, desde o planejamento das atividades de forma ativa e criativa até a sua execução, permitindo aos alunos, inclusive, perceber e avaliar diferentes estratégias aplicadas no processo ensino-aprendizagem. O Estágio de Docência supervisionado oferece um aprendizado prático na formação do docente enfermeiro. Com isso, a experiência na docência e produção de pesquisas, certamente proporcionará um contingente de mestres mais preparados para o enfrentamento dos inúmeros desafios a serem superados para uma educação de nível superior mais qualificada.

Conclui-se que o Estágio de Docência cumpriu seus objetivos, uma vez que possibilitou a aquisição de experiência na docência, permitindo a melhoria do desempenho da mestranda na prática docente e promovendo a articulação da graduação e pós-graduação.

\section{Referências}

1. Pimentel V, Mota DDCF, Kimura M. Reflexōes sobre o preparo para

a docência na pós-graduação em enfermagem. Rev Esc Enferm USP.

2007;41(1):161-4.

2. Chamliam HC. Docência na universidade: professores inovadores na USP. Cad

Pesqui. 2003;1(118):41-64.

3. Coordenação de Aperfeiçoamento de Pessoal de Nível Superior (BR).

Diretrizes para implantação do estagio de docência na graduação. Anexo do

Ofício Circular n. ${ }^{0}$ 028/99/PR/CAPES.

4. Coordenação de Aperfeiçoamento de Pessoal de Nível Superior (BR).

Resolução n. 013/00, de 27 de abril de 2000. Regulamento do Programa de

Demanda Social - DS. CAPES; 27 abr 2000; Seção 1.

5. Coordenação de Aperfeiçoamento de Pessoal de Nível Superior (BR). Portaria

n. ${ }^{76}$, de 14 de abril de 2010. Regulamento do Programa de Demanda Social -

DS. CAPES; 14 abr 2010; Seção 1.

6. Coordenaçẫo de Aperfeiçoamento de Pessoal de Nível Superior (BR). Portaria

n. 52, de 26 de setembro de 2002. Regulamento do Programa de Demanda

Social - DS. CAPES; 26 set 2002; Seção 1.
7. Cunha MI. Diferentes olhares sobre as práticas pedagógicas no ensino superior: a docência e sua formação. Educação. 2004;3:525-36.

8. Universidade Federal do Amazonas. Escola de Enfermagem de Manaus. Projeto Pedagógico do Curso Enfermagem Currículo 2009/1. Programa da disciplina Educação em Saúde,Manaus: UFAM; 2012.

9. Lopes AO. Relação de interdependência entre ensino e aprendizagem. In: Veiga IPA. Didática: o ensino e suas relaçōes. 6a ed. São Paulo: Papirus; 1996. p. 105-14.

10. Barbosa AS, Vidal LM, Duarte ACS, Boery EM, Boery RNSO, Sales ZN. Práticas docentes no ensino superior: relato de experiência em estágio de docência. REMPEC Ens Saúde Amb. 2011;4(1):18-33.

11. Freire P. Pedagogia da autonomia. São Paulo: Paz e Terra; 2004.

12. Associação Educacional Dom Bosco. Estágio docência: um estudo no programa de pós-graduação em administração da Universidade Federal de Lavras [Internet]. [citado em 2012 Jun 24]. Disponível em: http://www.aedb.br/ seget/artigos09/521_EnEPQ316[1].pdf. 